\title{
The Concept of 'Integrative and Personalized Health Care"
}

\author{
Peter Heusser ${ }^{a, b}$ \\ a Senior Professorship für Medical Anthropology, Witten/Herdecke University, Herdecke, Germany; \\ ${ }^{\mathrm{b}}$ Institute for Integrative Medicine, Faculty of Health, Witten/Herdecke University, Herdecke, Germany
}

Based primarily on patient needs and public demand, the concept and practice of 'integrative medicine' has gained increasing popularity and interest among health care professionals and academic research institutions. Coined by a German internist, the term 'integrative medicine' originally designated the integration of evidence-based forms of alternative or complementary treatments into conventional medicine [1]. This idea gradually transformed into to a more general concept of integrative medicine, including the integration of different medical approaches, a new attention to the whole person and the practitioner-patient relationship, the specific issues of health, and new forms of inter-professional cooperation [2].

In line with this tendency, the Witten/Herdecke University (WHU) established 'Integrative and Personalized Health Care' as the main common research focus of the Faculty of Health in $2009[3,4]$. In its report on the re-accreditation of the WHU in 2011, the German Council of Science and Humanities acknowledged this research focus as 'conclusively defined and basically suitable for the different disciplines and departments represented in the faculty to participate' [5]. This includes the Departments of Medicine, Nursing Sciences, Psychology and Psychotherapy, and Dentistry, each with its various disciplines, chairs, and institutes.

In this concept, 'integrative' designates the meaningful integration of different medical disciplines and treatment options into a patient-centered health care policy, based on a comprehensive perception of the patient, an intact practitioner-patient relationship, scientific evidence, and inter-professional co-operation, much in the sense of the Academic Consortium for Integrative Medicine and Health [2]. 'Personalized (or individualized) medicine' is used in an overarching humanistic sense of 'person'-orientation, including both 'personalized medicine' as the use of individual genetic and molecular markers for diagnostic, preventive, and therapeutic purposes, and 'person-(or patient)-oriented' health care, accounting for patients as individuals in the context of their biological, psychological, social, spiritual, cultural, and economic dimensions. The term 'health care' encompasses functional and systemic aspects of health care in relation to individuals, including the interfaces between diagnosis, treatment, curative care, rehabilitation and palliative care, the co-operation between different health professions, health promotion and prevention, health economy and other societal resources, demographic change, and education of health care professionals $[3,4,6]$.

In 2012, the Institute of Integrative Medicine (IfIM) was founded at the WHU with the intention to create a structured forum for exchange and collaboration between WHU institutions whose disciplines, research focuses, research and teaching methods are primarily based on a humanistic or person-centered approach to patients, care, and medical education, and to contribute from this side to the common research focus 'Integrative and Personalized Health Care' of the Faculty of Health at the WHU. This envelops the Chair for Theory of Medicine, Integrative and Anthroposophic Medicine, the Integrated Curriculum of Anthroposophic Medicine, the Professorship for Spirituality, Quality of Life, and Coping, the Professorship for Integrative Neuromedicine, the Professorship for Integrative Child and Adolescent Medicine, the Senior Professorship for Medical Anthropology, the Chair for the Fundamentals of Psychology, the Chair for Research Methods and Statistics in Psychology, singular researchers from fields such as Neonatology, Nursing Sciences, and Education, and the affiliated external Institute for Applied Epistemology and Medical Methodology in Freiburg. This supplemental issue of Complementary Medicine Research presents an overview over a selection of research topics and projects from the IfIM whose aim is to develop an integrative and person-oriented approach to health care and medical education, and thus to contribute to the overall research focus of the Faculty of Health at the WHU.

\section{KARGER}

(c) 2017 S. Karger GmbH, Freiburg

Fax +497614520714
Prof. Dr. med. Peter Heusser, MME (UniBE) Senior Professorship for Medical Anthropology Institute for Integrative Medicine, Faculty of Health, Witten/Herdecke University Gerhard Kienle Weg 4, 58313 Herdecke, Germany peter.heusser@uni-wh.de 


\section{References}

1 Thilo-Körner DGS: Naturheilkunde im Rahmen der integrativen Medizin: ein zukunftsorientiertes Konzept. Ärztezeitschrift für Naturheilverfahren 1994;35:613626.

2 Academic Consortium for Integrative Medicine \& Health: Definition of Integrative Medicine and Health. www.imconsortium.org/about/about-us.cfm (last accessed October 30, 2016).
3 Heusser P. Integrative and Personalized Health Care. www.uni-wh.de/en/health/forschung-gesundheit/ integrative-and-personalized-health-care, 2011 (last accessed October 29, 2016).

4 Heusser P: Towards Integration of 'Personalised' and 'Person-Centred' Medicine: The Concept of 'Integrative and Personalised Health Care'; in Vollmann J, Sandow V, Wäscher S, Schildmann J (eds): The Ethics of Personalised Medicine. Critical Perspectives. Surrey, UK, Ashgate Publishing LTD, 2015, pp 77-83.
5 Wissenschaftsrat: Stellungnahme zur Reakkreditierung der Privaten Universität Witten/Herdecke (UW/H) Berlin, Wissenschaftsrat, 2011, pp 100-101.

6 Heusser P, Neugebauer E, Berger B, Hahn E: Integrative and personalized health care - requirements for a timely health-care system (in German). Gesundheitswesen 2013;75:151-154. 